\title{
Acquisition System for Photovoltaic Panels with Data Storage in Remote Server Platforms Using Open Source Platforms Raspberry Pi and Arduino
}

José Ilton de Oliveira Filho, Wilk Maia Coelho, Marcos Eduardo Do Prado Villarroel Zurita, Mateus de Melo Araújo and Yago Borges Moreira

Department of Electrical Engineering, Federal University of Piaui, Teresina 64049-550, Brazil

\begin{abstract}
This paper consists of a prototype for a data acquisition system connected via wireless network for data storage on a remote server. This study presents the acquisition board and the operating principle of the whole system developed starting at the measurement of data up to its storage on a remote server. Using a remote server connected to the Internet implies the possibility of analysis, manipulation and control of such data from anywhere in the world.
\end{abstract}

Key words: Photovoltaic panel, acquisition, remote server.

\section{Introduction}

Brazil has a great potential for solar energy throughout the year, as a country located mostly in the intertropical region [1, 2]. With the use of solar energy, Brazil would has long-term benefits, enabling the development of remote areas where the cost of electrification by conventional network is too high in relation to the financial return on investment, regulating the energy supply in drought situations, decreasing dependence on the oil market and reducing greenhouse gas emissions in the atmosphere, as set out in the Kyoto Conference [3].

Ranhotigamage and Mukhopadhyay [4] claim that, there is an increasing need to monitor the behavior of photovoltaic panels. The understanding of different factors and light conditions are important to extract maximum power from a panel or a panel array. Katsuya, Shigeyasu, and Go [5] and Phelps, Lo and Michael [6], claim that this can be achieved by plotting the I-V characteristics of panels or arrays of

Corresponding author: José Ilton de Oliveira Filho, electrical engineer, research fields: microprocessors, embedded systems, renewable energies, acquisition systems and control systems. panels under different atmospheric conditions. Several studies were conducted to measure the curve I-V-P, through different types of data acquisition systems, and then, they were used to control the maximum power point so as to have a greater utilization of the panels [7].

The large-scale integration of renewable resources requires a thorough analysis of their impact on the electric generation system. One of the main problems related to these types of resources is the stability of the electrical system, due to the unpredictable variations of renewable resources [8]. The output of the PV generator shows variations due to the unpredictable sun's movements and climate conditions [9]. Because of it, the stability of a photovoltaic system requires recordings of your data over large periods [10].

There are numerous market data acquisition systems and in the last decade, there has been the emergence of various works aimed at cheapening and improving the efficiency of these systems. Most of them use physical connections to transfer data and, in almost all cases, an ordinary desktop computer is used to generate graphs and process the acquired data. Microprocessors, used in these systems are only used 

Platforms Using Open Source Platforms Raspberry Pi and Arduino

to obtain the analog and values converted into digital data. Parashar and Dhankhar propose in their work [11], the use of a wireless network, significantly reducing the cost of communication of an acquisition system in a small geographical area. In recent work, Y. L. Soon, K. B. Gan, and M. Abdullah propose the replacement of an ordinary computer for Raspberry PI SID data acquisition system, leading to a cheaper and improved data accessibility [12].

This paper presents the proposal to provide a viable and operating system for the acquisition, storage, processing and control of data without the need for an external computer for data processing and all communication done wirelessly.

\section{Methodology}

\subsection{Principles of Operation}

For this work, we used two open source development platforms, the Arduino and Raspberry Pi platform. The Arduino platform is designed with a microcontroller that can be programmed in $\mathrm{C}++$ with the help of own libraries, having a rich library of sample programs with plate features, available for download online [13]. The analog ports of this platform are configured to acquire instantaneous readings of voltage values present in them. The microcontroller (uC) ATMEGA328P, manufactured by Atmel, is responsible for the processing performed on the Arduino board.

The ATMEGA328P is considered a high performance uC, with low consumption, with operating current around $0.2 \mathrm{~mA}$. It has $1 \mathrm{~KB}$ of EEPROM memory, 2 KB of SRAM, 6 PWM channels, 8 digital channels and 6 analog channels; its operating voltage is 1.8 to 5.5 volts, the clock can be from 0 to $20 \mathrm{MHz}$ and has a universal serial USART and SPI interface $[14,15]$.

As a server, we used the Raspberry Pi, a low-cost ARM-based processor architecture, the size of a credit card computer, which connects to a monitor or TV and uses common keyboard and mouse. It is a small device that allows people of all ages to explore the computer and learn how to program in languages like Scratch and Python. With it, you can do everything you would expect from a desktop, from surfing the internet, playing videos in high definition to create spreadsheets, documents and play games [16].

Using the Arduino, it elaborated a data acquisition system from a number of sensors coupled to the photovoltaic panels. After data acquisition, the data are then transmitted by an RF transmitter to the server. Fig. 1 shows this system.

\subsection{System Implementation Details}

This data acquisition system focused in 3 different variables: temperature, current and voltage. For acquisition of the voltage, we used a voltage divider, designed with a factor of 1/6 between the level sent to the microcontroller and the output of the photovoltaic panel. For the current measurement, we used a power

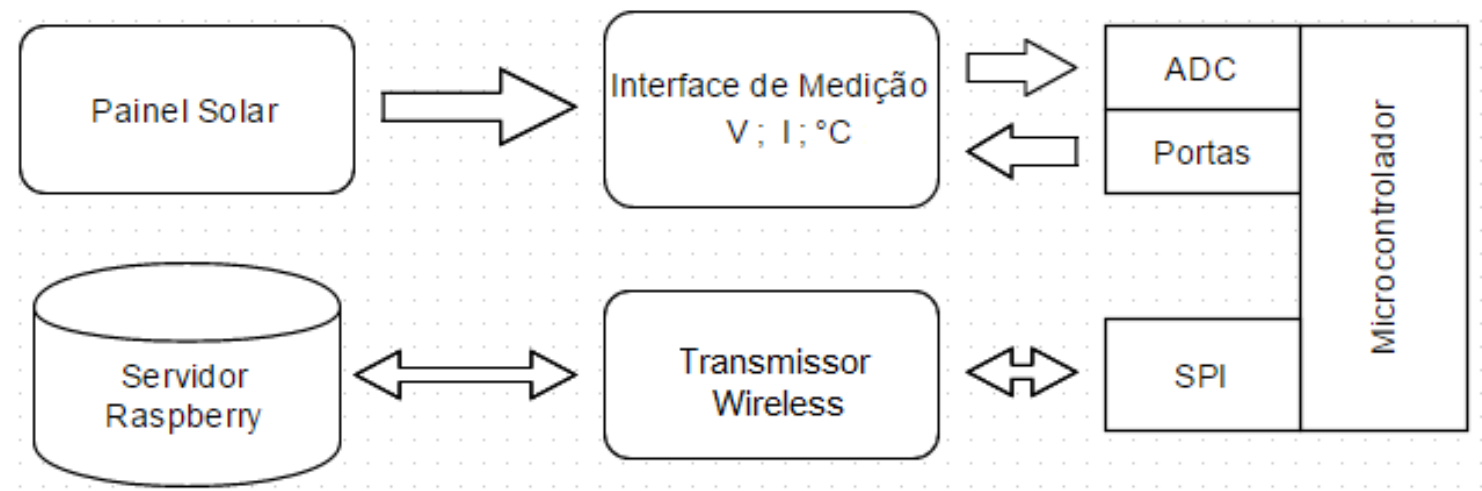

Fig. 1 Topology. 
resistor in series with the system load and the measured voltage level on it. The current was then calculated according to Ohm's Law. A LM35 sensor measured the temperature of the panel. This sensor is a Centigrade temperature linearly proportional output voltage integrated circuit. The schematic of acquisition board is shown in Fig. 2.

An Arch Linux ARM distribution $\mathrm{v}^{* 2014.06 *}$ on a 2 GB microSD card was used on a Raspberry Pi model B (rev. 2). Development tools have been updated and were installed packages of Python and control library of input and output ports for that language and the language $C$. An open source implementation of the RF24 was set up to interface the connection between the operating system and the transreceiver module [17]. An apache server was set up to implement an http server, allowing remote access to data collected without the need for specific expertise in Linux environment.

Using the transceiver module nRF24L01 + interfaced by SPI connection Raspberry, a star-type network topology is implemented, as shown in Fig. 3, based on the DHCP model in which the server records each new client with a local code for communication, similar to IP.

\section{Results Observed}

The system described in previous section was implemented, and during the period from 08:30 to 18:00 of a day, every 5 minutes, voltage data, temperature and current were harvested by acquisition system implemented with Arduino and sent to remote server. The server was then responsible for storing these values in text files for further analysis.

Graphics of the results obtained was generated using the matplotlib tool [18], in Python. These are shown in Fig. 5, as Fig. 4 gives an overview of the system designed and used for the measurements.

The results show a consistency in the voltage values obtained by the panel during the measurement period, with some clashing points slightly from the other, in the period from 11 to 16 hours. A similar effect is found in the current chart. This implies a constancy in the power supplied by the system during the day until about 16:30.

It is common there is an increase in the power delivered by the panel during the hours of peak sunlight. However, during these times, there is a

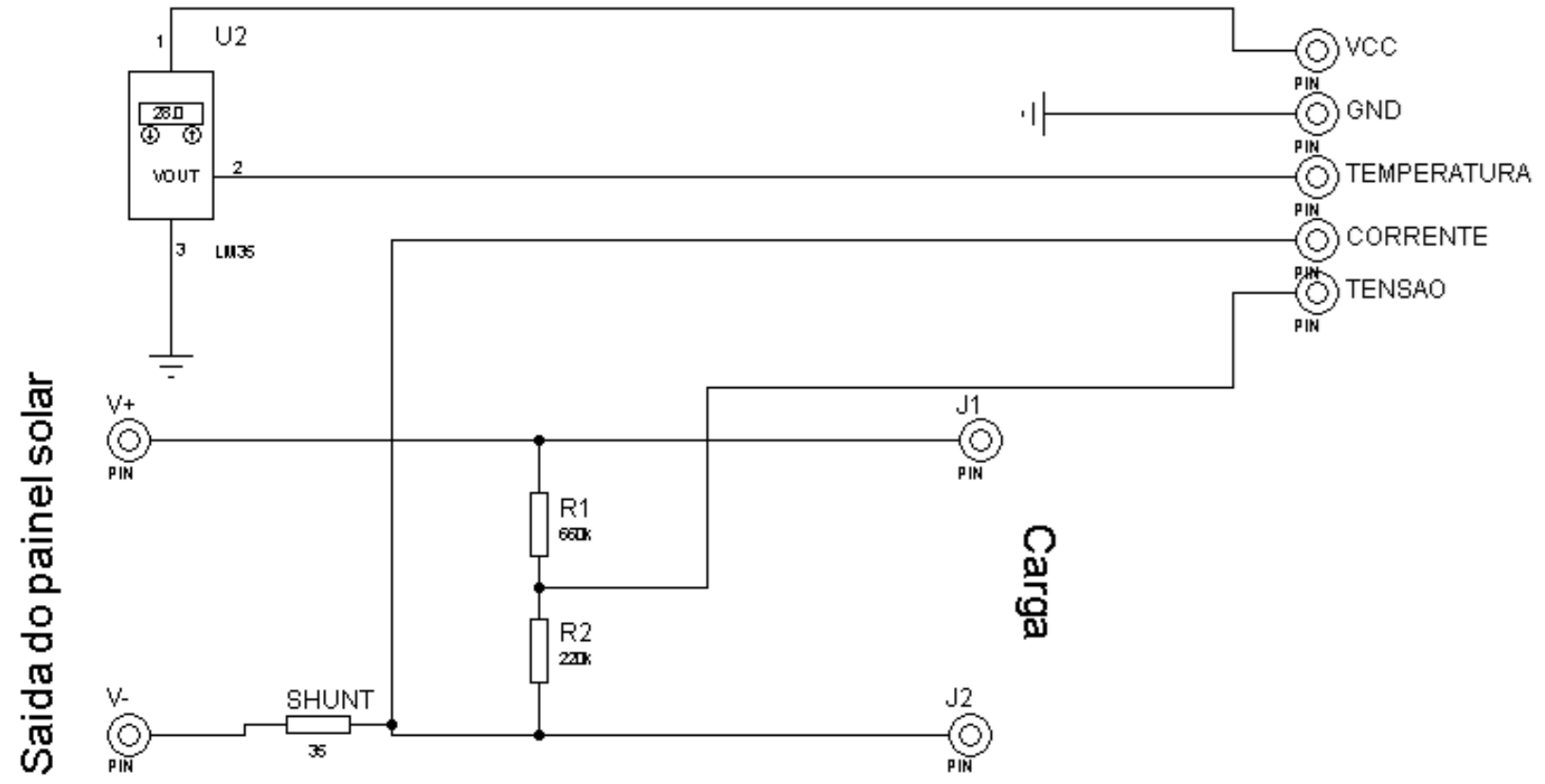

Fig. 2 Schematics of the acquisition board. 

Platforms Using Open Source Platforms Raspberry Pi and Arduino
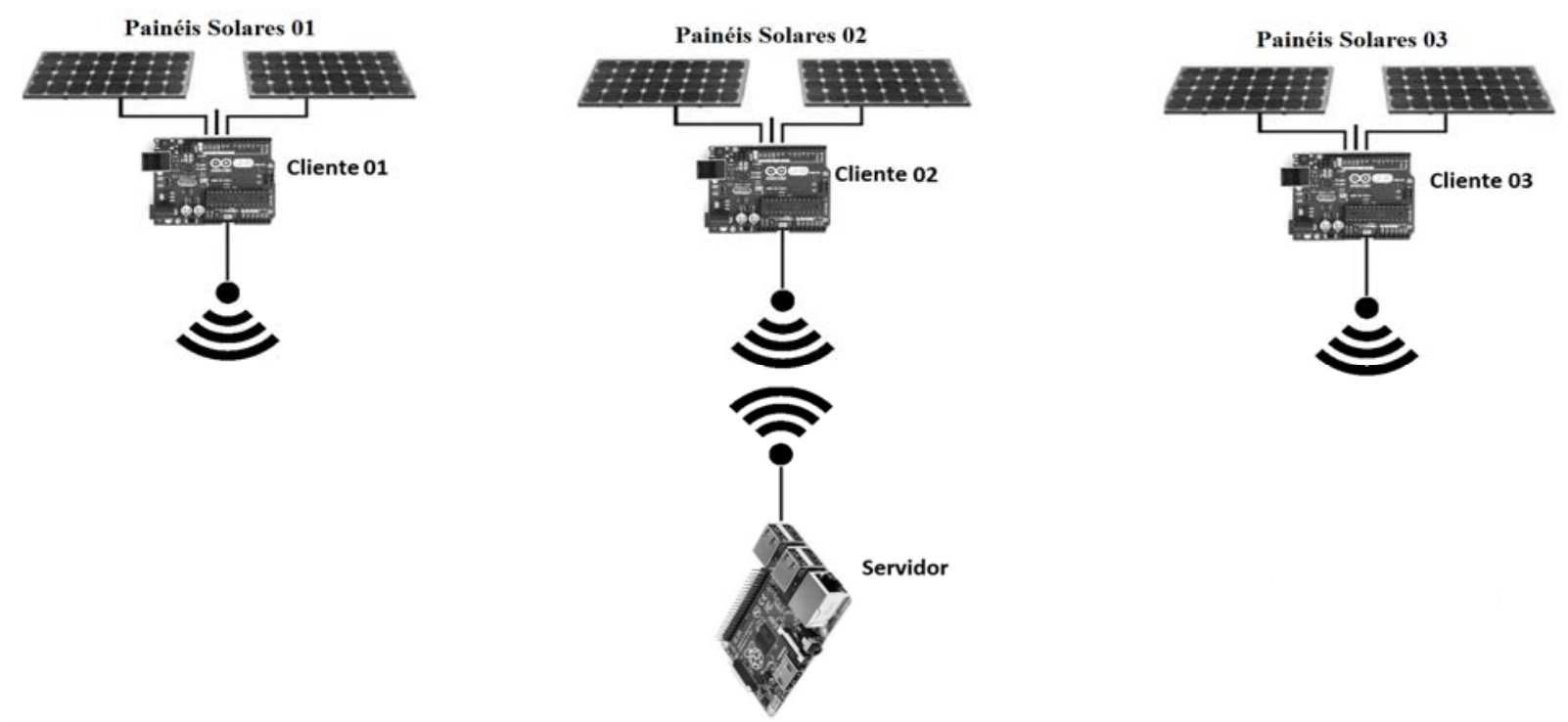

Fig. 3 Network between arduino and raspberry.

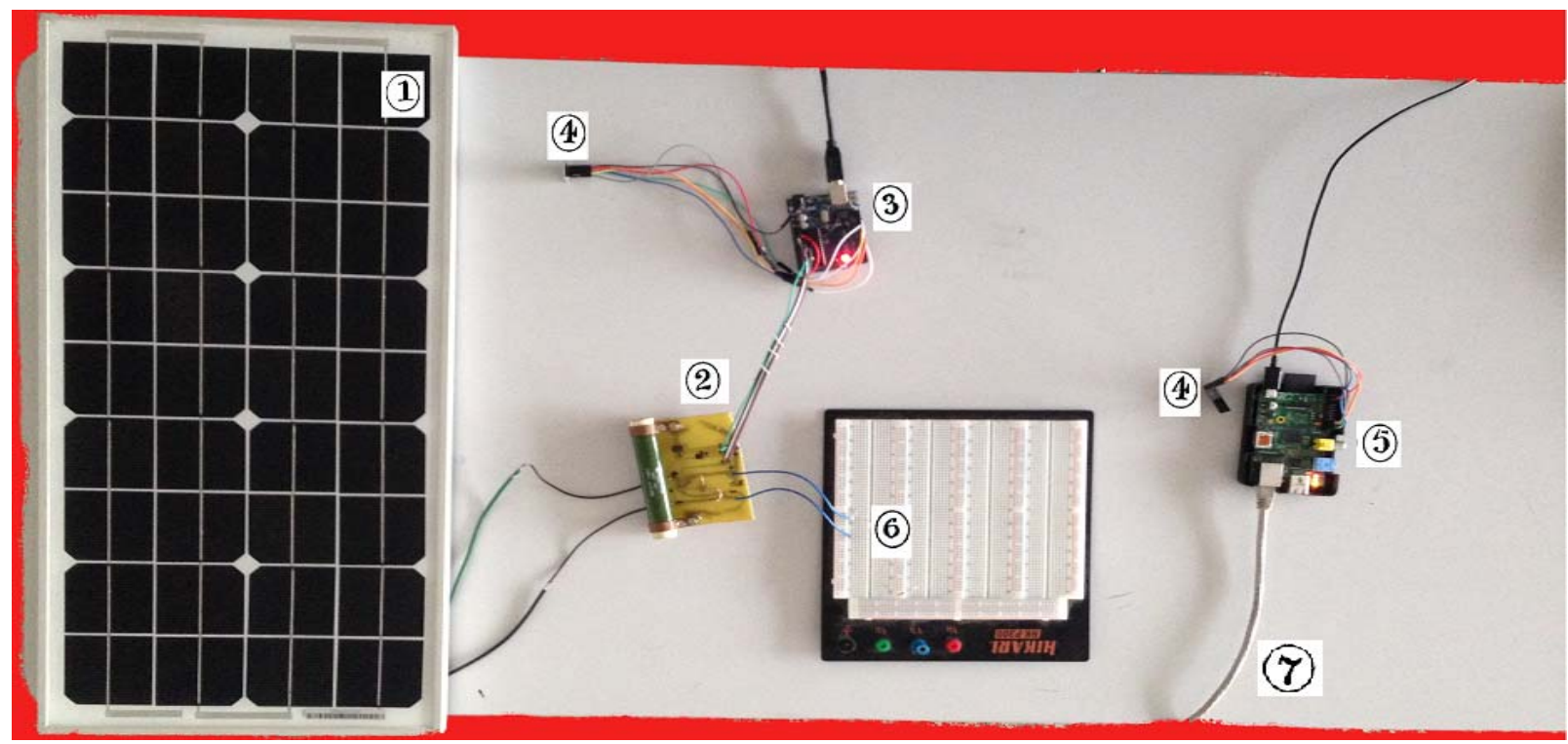

Fig. 4 (1) Photovoltaic panel; (2) Acquisition board; (3) Arduino; (4) 2.4 Ghz wireless transmission module; (5) Raspberry; (6) Output for load; (7) Internet connection cable.
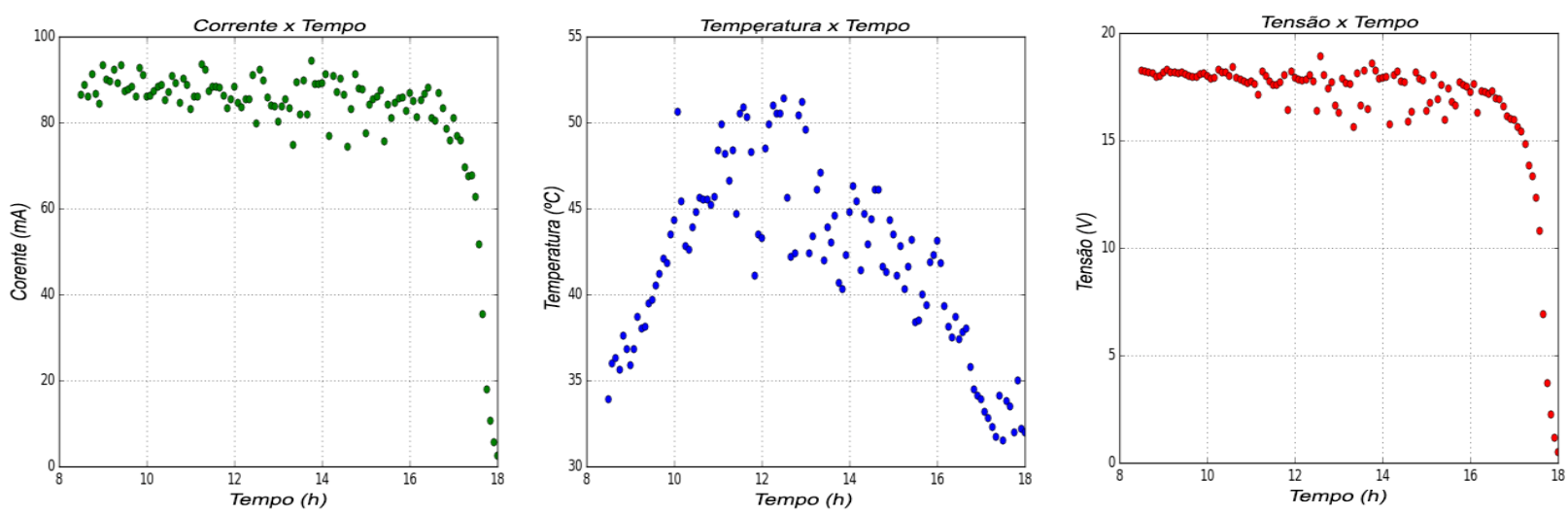

Fig. 5 Data acquired from the system on an 11 hours and 30 minutes period of time. Green for current, blue for temperature and red for voltage. 

Platforms Using Open Source Platforms Raspberry Pi and Arduino

considerable increase in the temperature of the photovoltaic panel. This may explain why the income drop in the transformation of solar energy into electrical energy, as an increase in temperature has a negative effect on this conversion process.

\section{Conclusion}

The system will be used to create a database in a period to be determined, where the acquisition will result in a power generated by the survey panel with short time intervals from 5 to 10 seconds. These data are needed to study the impact of variability of photovoltaics and its stability in power systems. Furthermore, this basic information will provide useful data for studies on the use of energy storage systems to increase the compatibility of the requirements photovoltaic power system.

As it does not use a conventional computer for storage and process the acquired data, we could achieve a cheaper acquisition system for photovoltaic panels. In addition to the price reduction, there is an improvement in the data transmission infrastructure through wireless transmission use, facilitating the inclusion of new points on the network and change location. Data acquisition of a whole array of solar panels becomes possible by configuring in a star network topology.

The proposed system makes use of a server run by a Raspberry $\mathrm{Pi}$, as the existing systems on the market use a more expensive computer, oversized for the project needs. This provides a cost savings in project implementation, given the lower investment required to purchase a Raspberry Pi module, when compared to a conventional computer.

There is also the possibility of using the central server connected to the network as a remote data source via the Internet. Thus, the data obtained by the acquisition system can be saved to remote servers or accessed remotely; and even some remote control technique with action or human supervision, can be implemented without the physical presence of a technician with the system, ideal for areas of difficult access.

\section{References}

[1] Tiba, C. 2000. Atlas Solarimétrico do Brasil: banco de dados terrestres, Editora Universitária da UFPE, Recife.

[2] Colle, S., and Pereira, E. B. 1998. "Atlas de Irradiação Solar do Brasil. Primeira Versão para Irradiação Global Derivada de Satélite e Validada na Superfície.” Instituto Nacional de Meteorologia (INMET), Brasília, p. 58.

[3] Martins, F. R., Pereira, E. B., and Echer, M. P. S. 2004. "Levantamento dos recursos de energia solar no Brasil com o emprego de satélite geoestacionário-o Projeto Swera.” Revista Brasileira de Ensino de Física 26 (2). São Paulo.

[4] Ranhotigamage, C., and Mukhopadhyay, S. C. 2011. "Field Trials and Performance Monitoring of Distributed Solar Panels Using a Low-Cost Wireless Sensors Network for Domestic Applications." IEEE Sensors Journal $11 \quad$ (10): 2583-90. doi: 10.1109/JSEN.2011.2150214.

[5] Katsuya, H., Shigeyasu, H., and Go, O. 2006. "Development of a High-Speed System Measuring a Maximum Power Point of PV Modules." In Proc. IEEE 4th World Conf. Record. Photovoltaic Energy Conversion, 2262-3.

[6] Phelps, R., Lo, B., and Michael, S. 2004. "Evaluation and Testing of the Solar Cell Measurement System Onboard the Naval Postgraduate School Satellite NPSAT1.” In Proc. 22nd AIAA Int. Commun. Satellite Syst. Conf. Exhibit (ICSSC), 1-8.

[7] Griesbach, C. R. 1996. "Fault-Tolerance Solar Array Control Using Digital Signal Processing for Peak Power Tracking.” In Proc. 31st Intersociety Energy Conversion Eng. Conf., 260-5. DOI:10.1109/IECEC.1996.552881.

[8] Pérez-Arriaga, I. J. 2011. "Managing Large Scale Penetration of Intermittent Renewables.” MIT Energy Initiative Symposium Framework paper, April 20, 2011.

[9] Mills, A. 2010. "Understanding Variability and Uncertainty of Photovoltaics for Integration with the Electric Power System.” Lawrence Berkeley National Laboratory, LBNL Paper LBNL-2855E.

[10] Petrescu, C., Lupu, C., Tudor, F. S., and Azzouzi, M. 2013. "Data Acquisition System for Recording of Photovoltaic Panel Power." In Proceedings of 2nd International Conference on Systems and Computer Science (ICSCS) Villeneuve d'Ascq, 26-7.

[11] Parashar, S., and Dhankhar, S. 2014. "Increase Efficiency of Solar Photovoltaic System by Data Acquisition Process.” 2014 IEEE 6th India International Conference 
on Power Electronics (IICPE), Kurukshetra, pp. 1-5. doi: 10.1109/IICPE.2014.7115741.

[12] Soon, Y. L., Gan, K. B., and Abdullah, M. 2015. "Development of Very Low Frequency (VLF) Data Acquisition System Using Raspberry Pi.” 2015 International Conference on Space Science and Communication (IconSpace), Langkawi, pp. 485-8. doi: 10.1109/IconSpace.2015.7283807.

[13] Arduino (2015). Arduino®. Disponível em: http://arduino.cc/. Acesso em: 22/ 07/ 2015.

[14] ATMEL, 8161D-AVR. 2009. MICROCONTROLLER with $4 / 8 / 16 / 32 k$ bytes in-system programmable flash. Disponível em: http://www.atmel.com/Images/doc8161.pdf > . Acesso em: 22/05/2015.
[15] Mota, A. A., Mota, L. T. M., Oliveira, V. C., and Trocopio, E. T. 2011. “Implementação de Medidor de Energia Elétrica em Plataforma de Hardware Livre Para Estudos de Comportamento de Redes Inteligentes.” XXXIX Congresso Brasileiro de Educação em Engenharia-COBENGE.

[16] Raspberry Pi Foundation. Raspberry Pi. Available in https://www.raspberrypi.org/. Access in: 22/03/2015.

[17] Seow, S. 2014. Arduino and Raspberry Pi driver/libraries for nRF24L01. Disponível em: < https://github.com/Stanley seow/ RF24>. Acesso em: 28/10/2015.

[18] Hunter, J. D. 2007. "Matplotlib: A 2D graphics environment." Computing In Science \& Engineering, IEEE COMPUTER SOC. 